\title{
Short Segment Hirschsprung Disease
}

National Cancer Institute

\section{Source}

National Cancer Institute. Short Segment Hirschsprung Disease. NCI Thesaurus. Code C101041.

The most common form of Hirschsprung Disease, this is characterized by a lack of nerve cells in the sigmoid colon and rectum. The bowel is not stimulated without innervation and obstruction ensues. Surgical intervention is necessary. 